\title{
REAL-TIME THERMAL MAPPING FOR HEAT \& COOL ARCHIPELAGOS OF BENGALURU, INDIA
}

\author{
Rajesh GOPINATH ${ }^{1 *}$, Aditya BANERJEE ${ }^{2}$, S. SACHIN ${ }^{2}$, Prakhar TIWARI ${ }^{2}$ and Sunny \\ WILSON ${ }^{2}$ \\ ${ }^{1}$ Department of Civil Engineering, BMSIT\&M, Bengaluru 64, India. \\ ${ }^{2}$ Department of Construction Technology and Management, AcIT, Bengaluru 107, India. \\ * corresponding author: dr.rajeshgopinathnair@gmail.com
}

\begin{abstract}
Blessed with a salubrious climate, the city of Bengaluru over the past few decades has constantly witnessed thermal discomfort owing to several Urban Heat islands that have mushroomed within the city. The subsequent increase in builtup area, consequent loss of productive agricultural lands/green zones, encroachment of surface water bodies coupled with the ill-preparedness of decision makers to handle the demand for land have invariably crumbled the natural micro-climate of the city. In this present research, an attempt has been made to detect the distribution of Urban Heat Islands in Bengaluru City by conducting real-time survey at 100 observatories marked across the entire urban \& rural locations; with thermohygrometers as per the W.M.O. guidelines. The study confirmed the violation of the Human Thermal Comfort Range in $9,83,98,99,98$ and 80 observatories for the monitoring at 6 AM, 9 AM, 12 PM, 3 PM, 6 PM and 9 PM respectively.
\end{abstract}

\section{Keywords:}

Bengaluru;

Islands;

Heat;

Thermal;

Urban.

\section{Introduction}

Urbanization is a major social and scientific change spreading around the globe [1]. In cities, concrete and asphalt have replaced most of the natural surfaces and vegetation cover, with automobiles and air-conditioners becoming potential anthropogenic heat sources [2]. These unprecedented developments have introduced irreversible changes in the climate of each and every city, with the formation of urban micro-climates called the 'Urban Heat Islands' (U.H.I.) [3].

Bengaluru city had long been considered as a 'Pensioner's Paradise'. Its inherent strength was considered to be its pleasant weather, which was even compared to that of London. However, it over the last few decades has urbanized and sporadically grown beyond rural fringes, at the expense of its natural surfaces. As a result, the detrimental changes have become faster and negative having a lasting impression on the temperature profile of Bengaluru as well [4]. As Bengaluru continues to constantly expand, the elevated temperatures are anticipated to rise higher. The ability to manage Urban Heat Islands and simultaneously also preserve the natural environment of Bengaluru is therefore a matter of key concern.

The effect of Urban Heat Island is well documented for several cases, but none have managed to cover a vast area with real-time monitoring, and hence the current study attempts to plug this gap in literature. Also though there are studies that had hinted of Bengaluru being host to the urban phenomenon; none had quantitatively evaluated its intensity. Present research attempts to fill this gap in the literature.

\section{Experimental methodology}

The land-use of Bengaluru city is very heterogeneous, and since a comprehensive examination into the regions of Bengaluru is beyond the scope of this research, a maximum total of one hundred potential sites having distinct land-uses (Water-bodies, grass \& green lands, industrial areas, residential areas, commercial areas, peak traffic areas, sports complex, important junctions, barren 
lands etc.), and capable of producing representative results were identified by 'Supervised Classification'.

Fig. 1 (Google Image) provides an eagle's eye view of entire study area demarcating the 100 observatories. Entire Bengaluru was considered for this mammoth survey, as also can be observed from the Satellite image that the observatories were located in and around the core of the city.

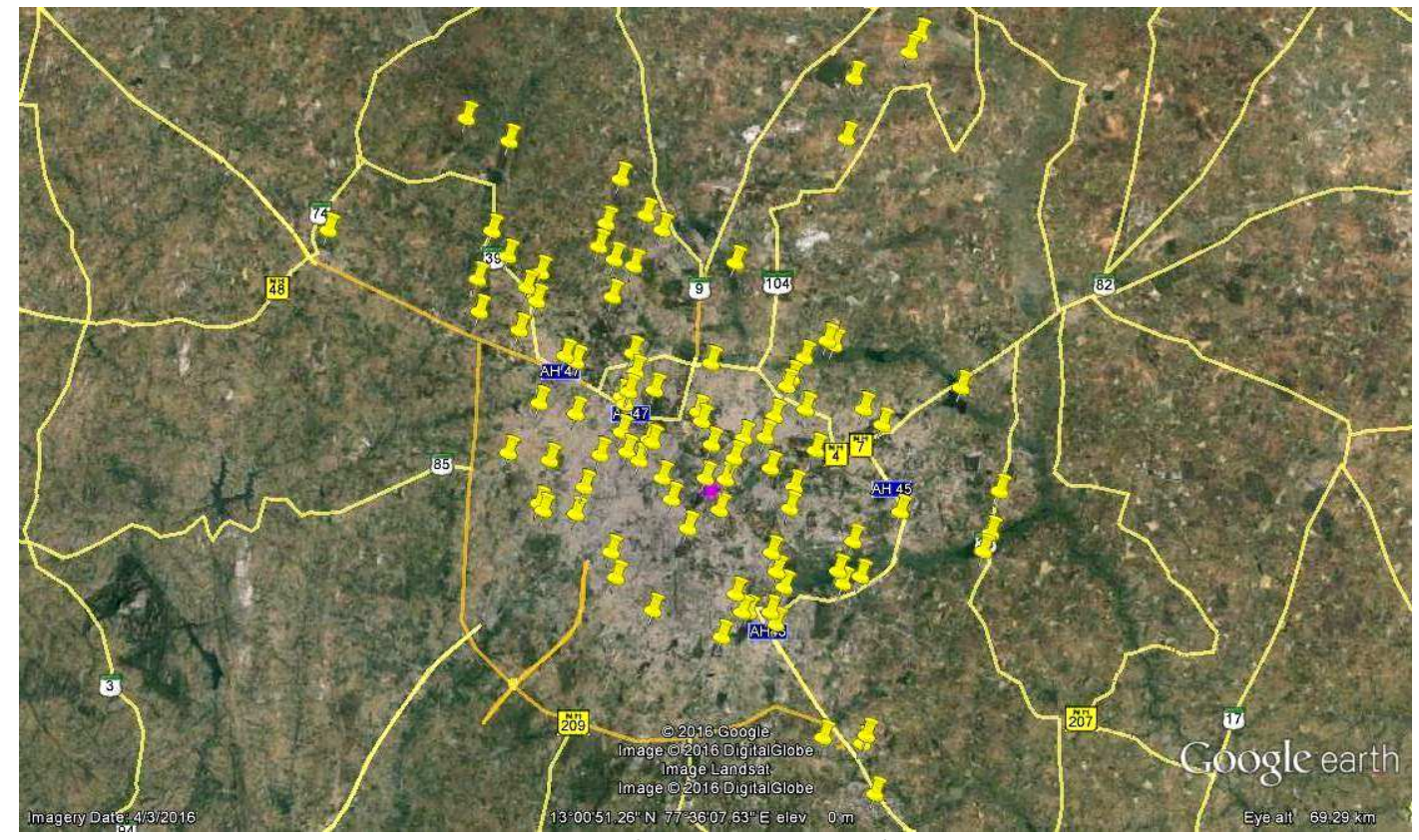

Fig. 1: Eagle's eye view for distribution of each observatory.

The ambient air temperature survey was done simultaneously across selected observatories distributed over 26 days on weekdays and weekends at 6 AM, 9 AM, 12 PM, 3 PM, 6 PM and 9 PM. On each day, a standard Reference Station (located in Bengaluru Rural) was constantly monitored to ensure normalization of data while analysis. This facilitated the comparison of Ambient Air Temperature Levels across observatories in the city for violation with Human Thermal Comfort Factor. The monitoring was carried out by adhering to W.M.O. norms [5], with the aid of Hand-held Digital Thermo-Hygrometers. Further, data representation and analysis involved plotting and drawing inferences about the temporal behavior across all observatories with construction of Isotherms from the normalized daily data. The determination of Urban Heat Island intensities completed the analysis segment. This was achieved by employing the equation (1), where $i$ represents the respective hour of observation [6].

$\Delta A T=A T_{\text {urban }}^{\mathrm{i}}-A T_{\text {reference }}^{\mathrm{i}}$.

\section{Results and discussion}

The Comparative Variation of Ambient Air Temperature about each observatory based on daily monitoring unveiled several revelations such as certain observatories with more urban features were always warmer than Reference Station, and observatories with least human disturbance were relatively cooler. While the maximum temperature was mostly observed at $3 \mathrm{PM}$, the least was usually observed at 6 AM. Figs. 2 to 7 showcase Isotherms of the complete study area at 6 AM, 9 AM, 12 PM, 3 PM, 6 PM and 9 PM respectively. Each temperature map clearly revealed the presence of several Urban Heat Islands within the study area.

Monitoring at 6 AM confirmed that 9 observatories had violated the Human Thermal Comfort Range of $18-28{ }^{\circ} \mathrm{C}$. It was also observed that the maximum intensity of $+6.8{ }^{\circ} \mathrm{C}$ was at a densely populated location (Shivajinagar), and the minimum intensity was $-5.8^{\circ} \mathrm{C}$ at Madiwala Lake. While monitoring at $9 \mathrm{AM}$, the study confirmed 83 violations of the Human Thermal Comfort Range. The maximum intensity was found to be $+11.2^{\circ} \mathrm{C}$ at an Industrial Area (Peenya) owing to the plumes and innumerous $\mathrm{AC}$ ducts. The minimum intensity was found to be $-5.5^{\circ} \mathrm{C}$ at Hessarghatta, a zone of 
Green-belt. While monitoring at $12 \mathrm{PM}$, there were 98 violations of the Human Thermal Comfort. It was being observed that the maximum intensity was $+9.6^{\circ} \mathrm{C}$ at $\mathrm{BIEC}$, due to the elevated anthropogenic heat emission from the AC vehicles. The minimum intensity was found to be $-11.2^{\circ} \mathrm{C}$ at IISc campus, a potential lung-space of Bengaluru city.

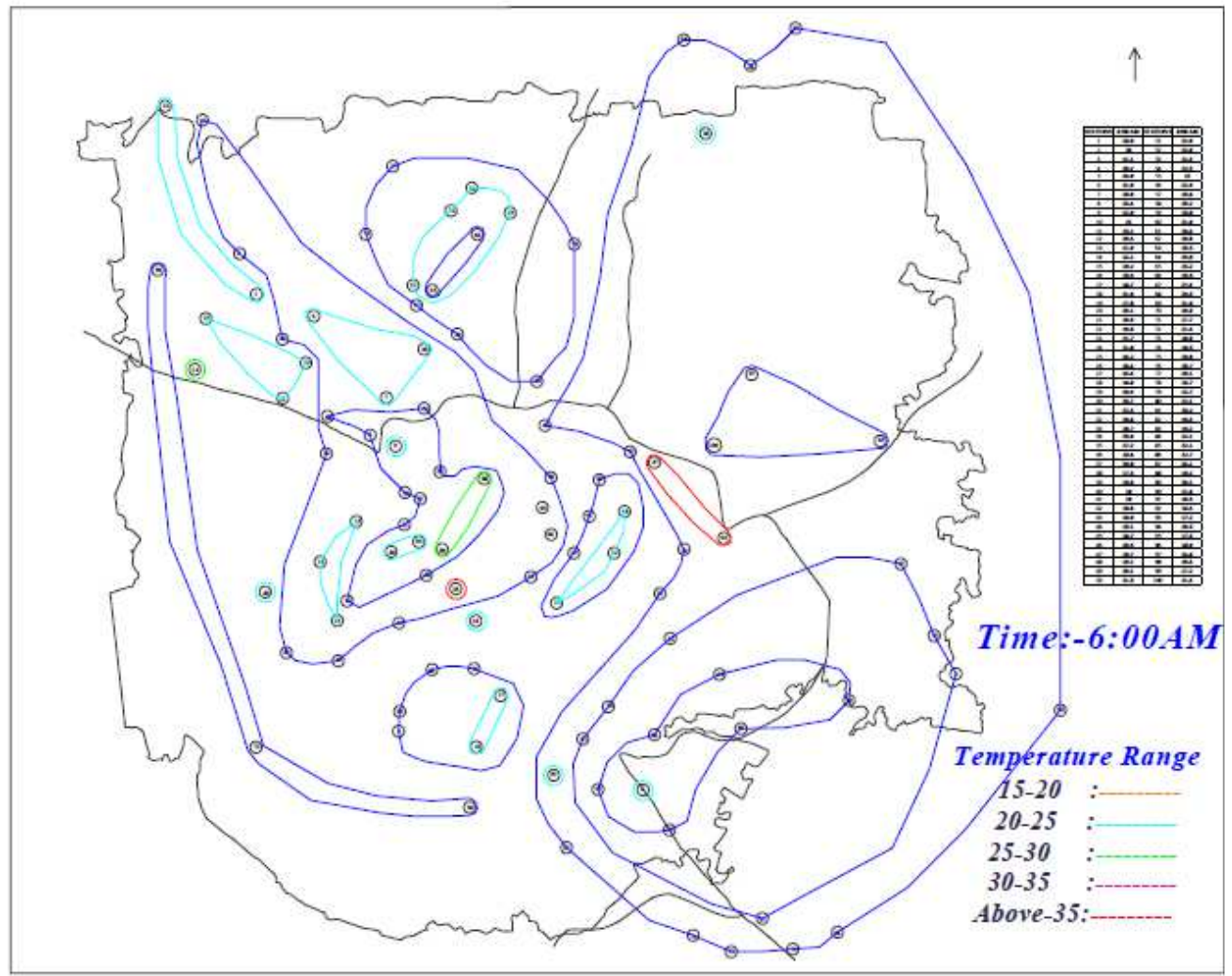

Fig. 2: 6 AM Isotherm for Bengaluru.

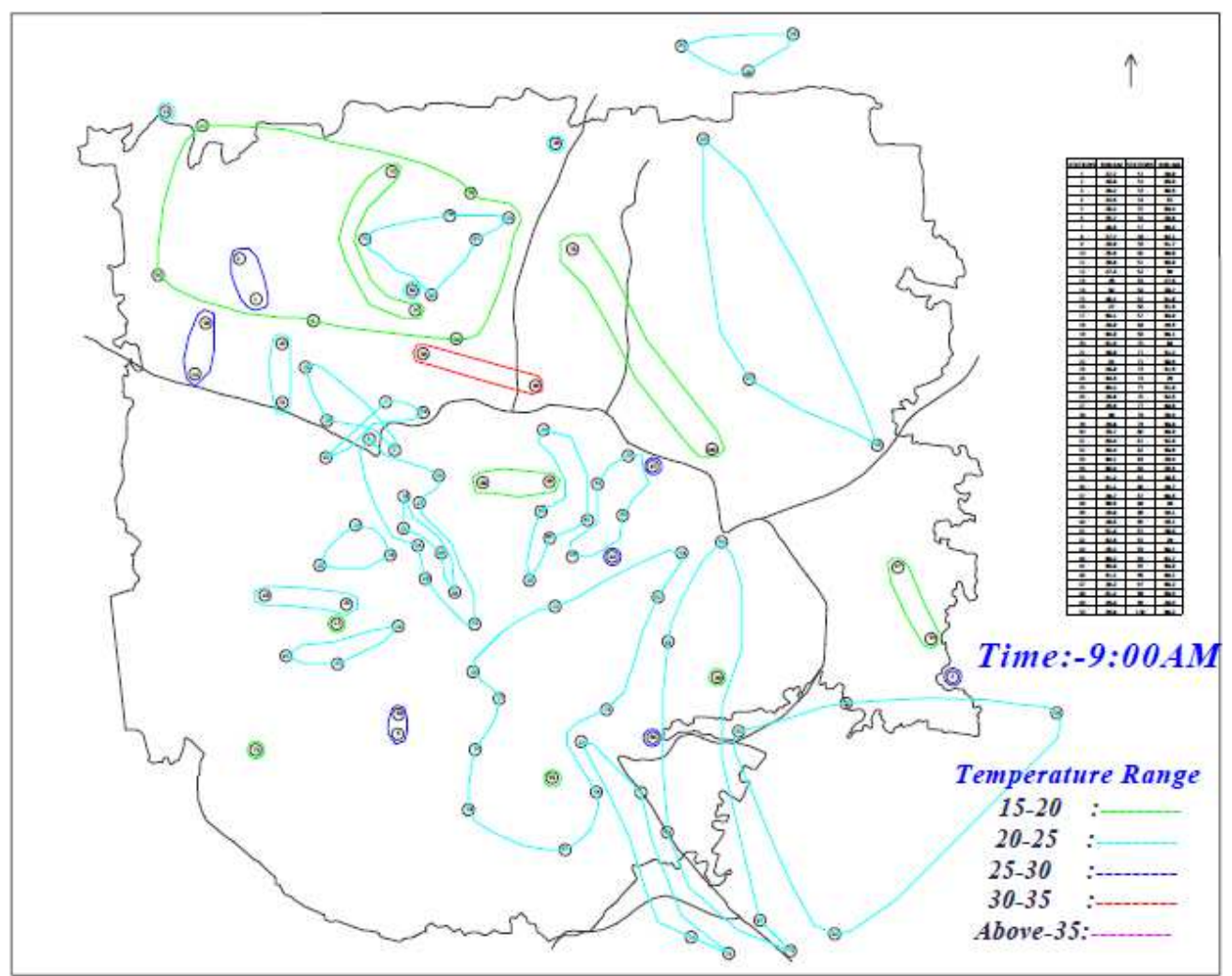

Fig. 3: 9 AM Isotherm for Bengaluru. 


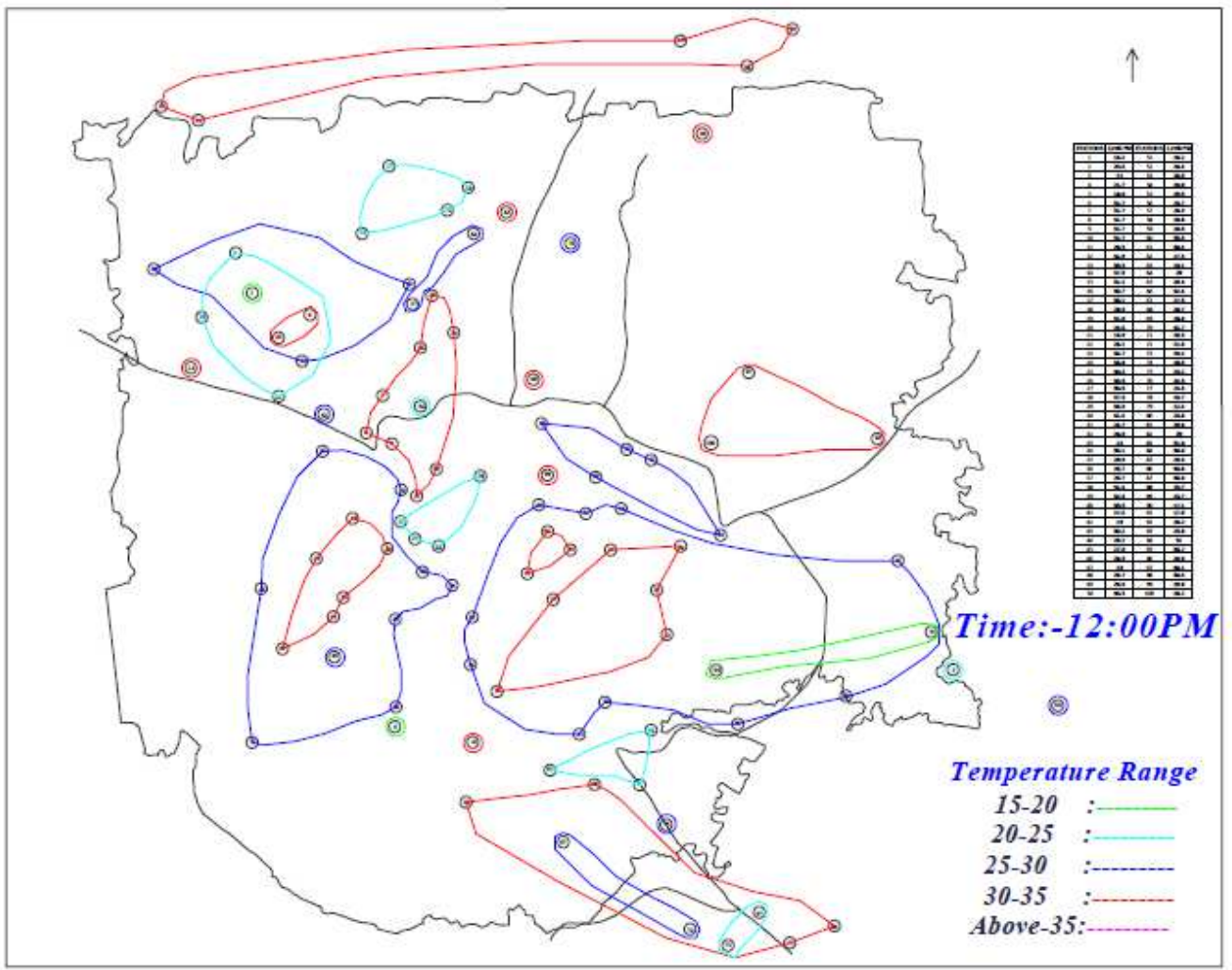

Fig. 4: 12 PM Isotherm for Bengaluru.

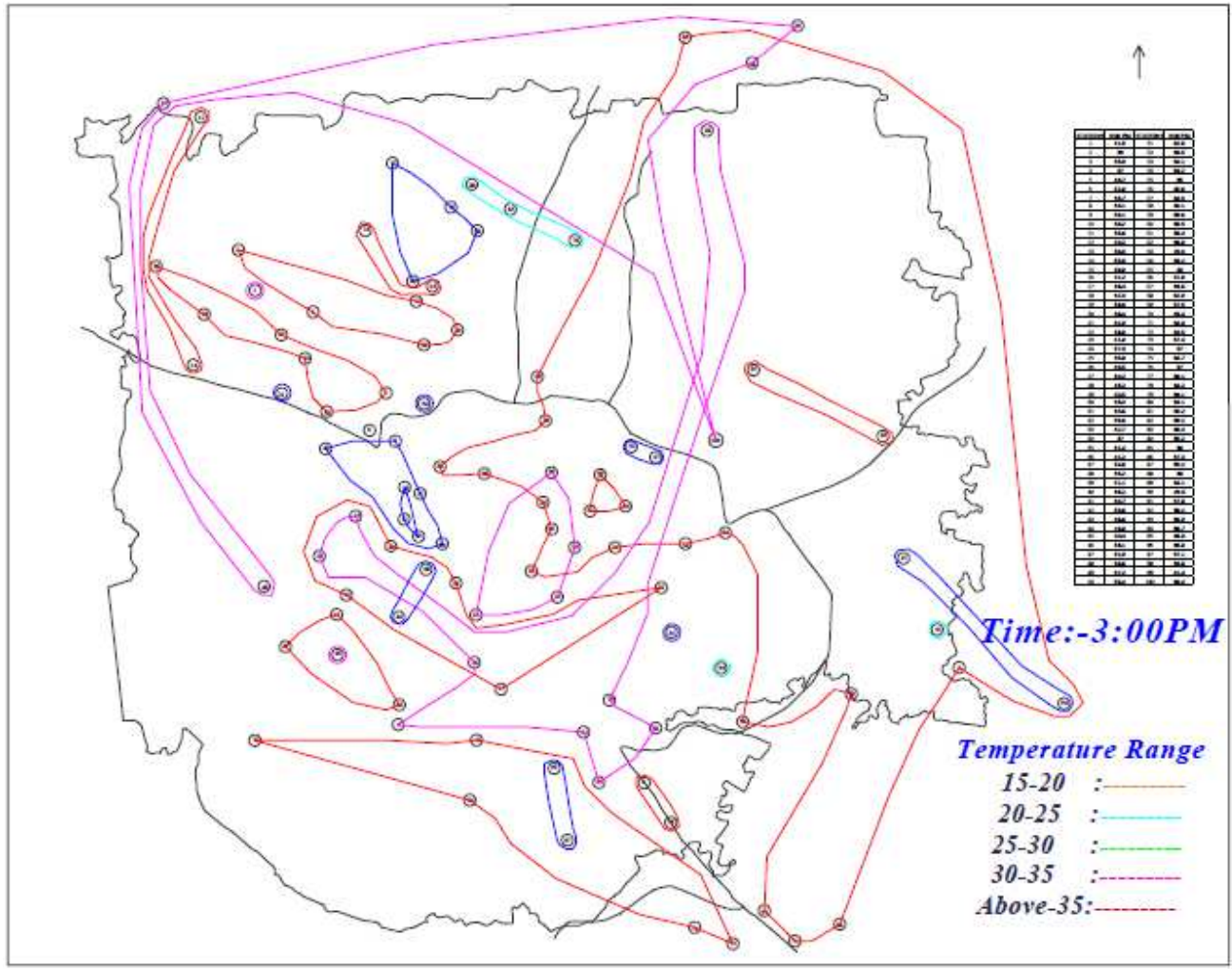

Fig. 5: 3 PM Isotherm for Bengaluru. 


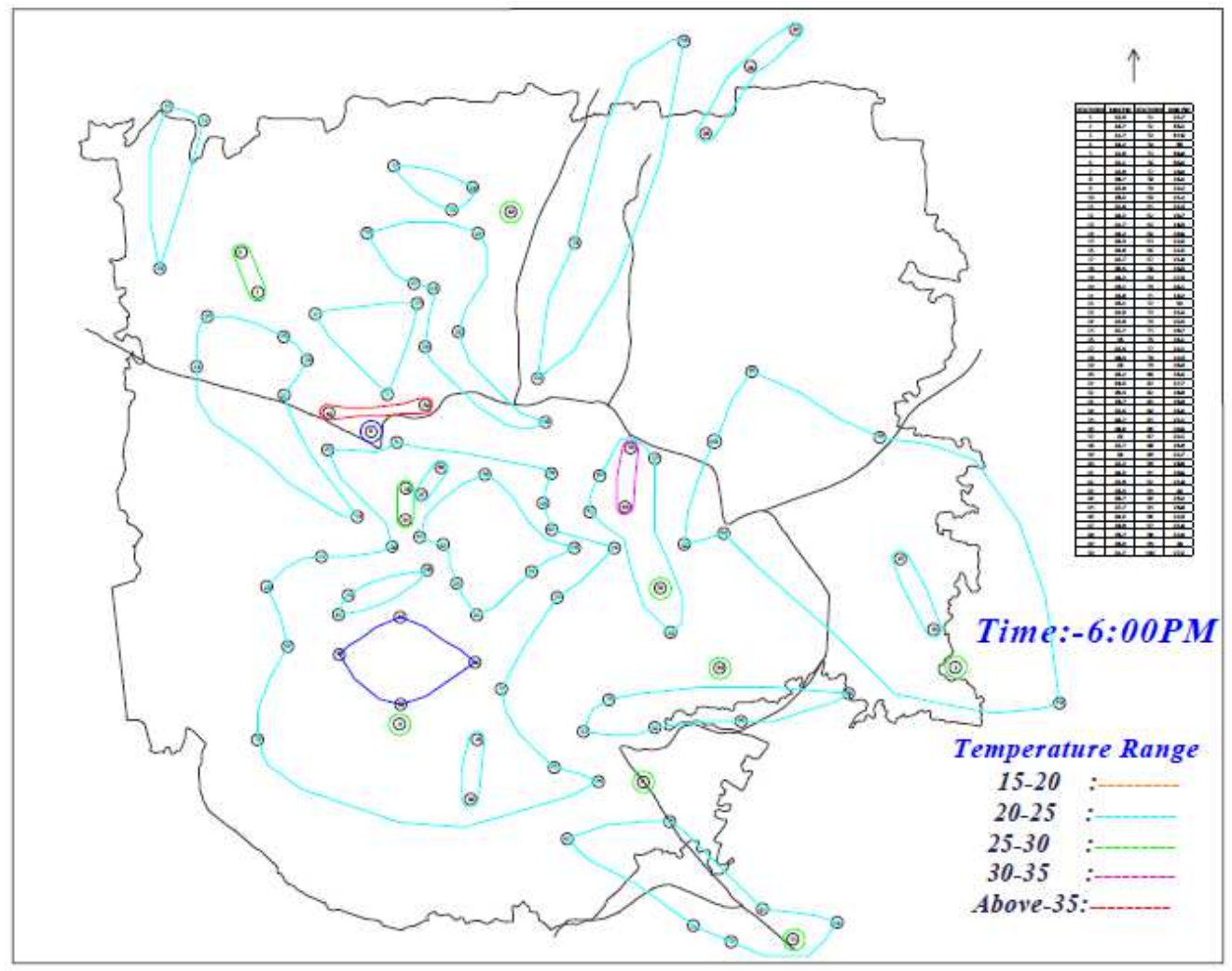

Fig. 6: 6 PM Isotherm for Bengaluru.

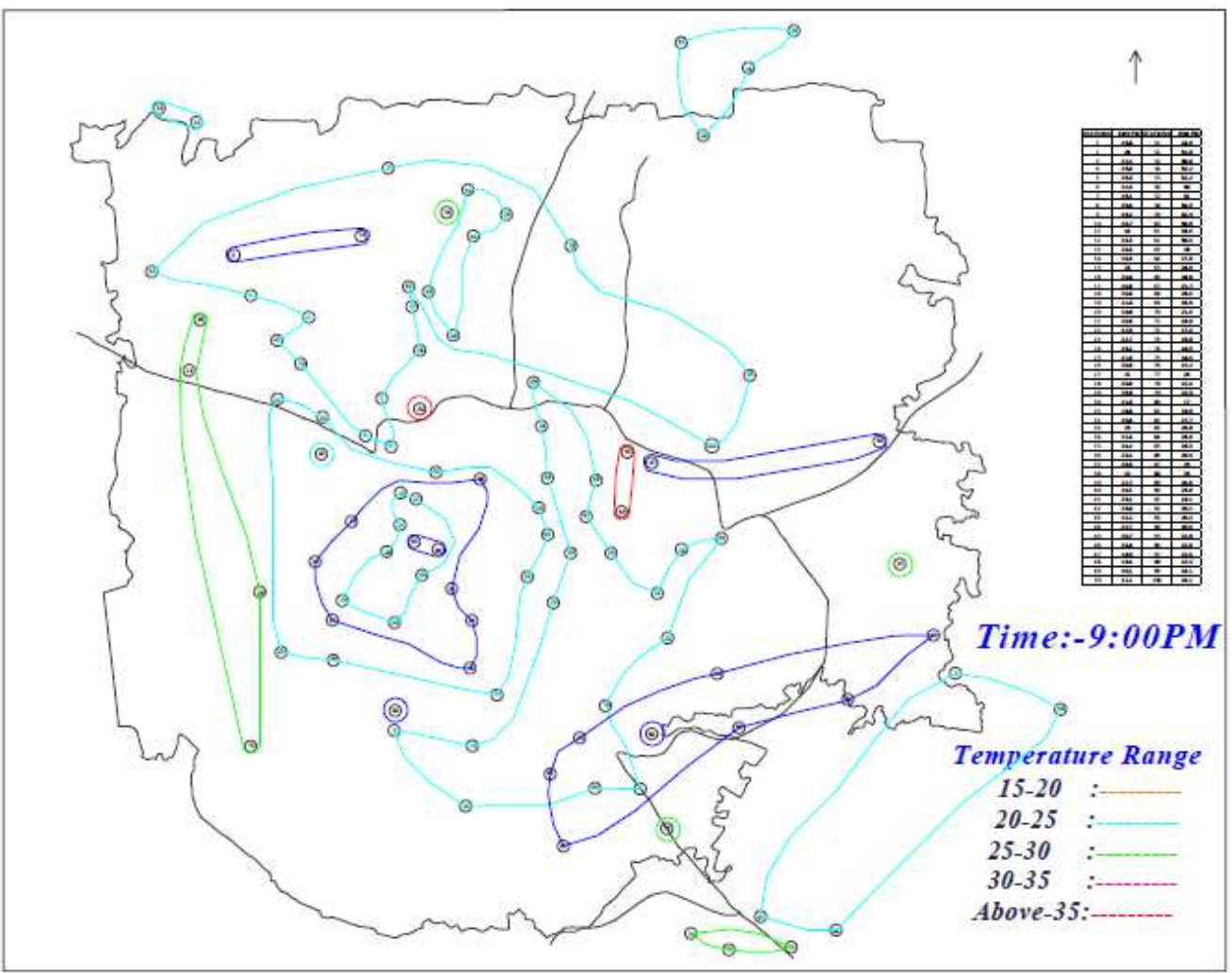

Fig. 7: 9 PM Isotherm for Bengaluru. 
While monitoring at $3 \mathrm{PM}, 99$ violations were documented. It was observed that the maximum intensity was $+12.9{ }^{\circ} \mathrm{C}$ at Bagalur Circle, a location having dense traffic volumes, and fugitive heat trappings of glass façade from commercial enclaves and AC vehicles. The minimum intensity was found to be $-3^{\circ} \mathrm{C}$ at the Campus of Indian Institute of Science, and the coolness could be attributed to its rich Canopy shading owing from its moderate Green-cover. While monitoring at 6 PM, the maximum intensity was found to be $+14.7^{\circ} \mathrm{C}$ at Kalyannagar on account of greater population of $\mathrm{AC}$ driven vehicles. The minimum intensity was found to be $-4.6^{\circ} \mathrm{C}$ at Yelahanka Lake owing to the Lakecover. Also the study confirmed 98 violations at $6 \mathrm{PM}$. While monitoring at $9 \mathrm{PM}$, the maximum intensity was $+11.1^{\circ} \mathrm{C}$ observed at Gokula Extension on account of dense vehicular movement. The minimum intensity was found to be $-1.7^{\circ} \mathrm{C}$ at Herohalli Lake. Also the study confirmed 98 violations at 9 PM.

\section{Conclusion}

The presence of several intra-Urban Heat Islands is majorly due to the inorganic growth of Bengaluru to satisfy its population growth and its subsequent varied demands; contributed by creation of several pockets of Urban Heat Islands due to net solar energy gain from the buildings, streets and sidewalks, improper canyon geometry and elevated surface temperatures. Realizing the severity that Urban Heat Islands can introduce to a community, it becomes mandatory to mitigate its ill-effects. The degree, to which the urbanized areas can seek advantage from reduction strategies, rests on a myriad measures both within and outside a community's control. Water surfaces in the form of Fountains and Trees in the form of Public Green Spaces, Private Gardens and Green Roofs facilitates a secondary cooling effect in urban landscapes; by moderating the microclimate as evapo-transpiration reduces ambient air temperature. Strategically, the use of preventive and corrective measures can enhance the effectiveness in strategies of mitigative objectives.

\section{References}

[1] TAYANC, M. - TOROS, H.: Urbanization Effects on Regional Climate Change in the Case of Four Large Cities of Turkey. Climatic Change, Vol. 35, 1997, pp. 501-524.

[2] HITCHCOCK, D. - GERO, G. - DIETSCH, N., C. and D.: Reducing Urban Heat Islands. Compendium of Strategies, U. S. EPA Office of Atmospheric Programs, 2002, pp. 1-52.

[3] AKBARI, H.: Potentials of Urban Heat Island Mitigation. Proc. International Conference Passive and Low Energy Cooling for the Built Environment, Santorini, Greece, 2005, pp. 11-22.

[4] GOPINATH, R. et al.: Change Recognition in Land-Cover Dynamics for Bangalore City due to Rampant Urbanization, using Quantum G.I.S. International Journal of Engineering, Business and Enterprise Applications, Vol. 13, Iss.1, 2015, pp. 34-36.

[5] Guide to Meteorological Instruments and Methods of Observation, Switzerland: Secretariat of the World Meteorological Organization, Chapter 1, 2006, I.1-1-I.

[6] GOPINATH, R. - BHANUMURTHY, P.R. - VIJAYALAKSHMI A.: RMA and Its Comparison over other Computational Approaches. International Journal of Mathematical Sciences \& Engineering Applications, Vol. 6, Iss.1, 2014, pp. 381-390. 